\title{
Using Activity Theory Successfully in Healthcare: A Systematic Review of the Theory's Key Challenges to Date
}

\author{
Fabian Wiser \\ University of Braunschweig \\ winfo-radar@tu- \\ braunschweig.de
}

\author{
Carolin Durst \\ Ansbach University of Applied \\ Sciences \\ carolin.durst@hs-ansbach.de
}

\author{
Nilmini Wickramasinghe \\ Deakin University / Epworth \\ HealthCare \\ n.wickramasinghe@deakin.edu.
}

$\underline{\mathrm{au}}$

\begin{abstract}
Collaborative tools in organizations become more and more apparent. These tools are being realized by novel information technology. Particularly, healthcare is a fast-evolving industry in terms of information system innovation. As the evolution is fast, and new systems are always error-prone due to socio-technical complexity, new analysis tools and methods for quality assurance must be adapted. In earlier research, we proposed Activity Theory as a fitting analysis tool due to the reason that it has advantages over other HCI theories, such as Actor-Network Theory or Distributed Cognition. However, several limitations became apparent during our studies. In the present work, we are conducting a systematic literature review of activity theoretical limitations and challenges to provide design guidelines for an improved version of Activity Theory. These implications can help to develop more advanced Activity Theory concepts and contributions; which in turn can improve the analysis results of socio-technical systems in healthcare.
\end{abstract}

\section{Introduction}

Novel information technologies enable computersupported cooperative work (CSCW), and foster new ways of digitally enhanced collaboration. In particular, healthcare is a fast-evolving industry in terms of information system innovation [42]: Recent advancements in medical technology have given birth to the electronic health record, computerized physician order entry systems and point-of-care patient engagement solutions (PoCS).

These systems are characterized by their technical complexity, the critical binding to human life and wellbeing. Therefore, they need to be easy to use, explicit and adapted to the social context they are embedded in. Thus, a socio-technical analysis before, while, and after implementing and piloting such systems is seen as fruitful [52].

For these types of analysis, there exist various explanatory theories in science [16]. In earlier research, we proposed Activity Theory (AT) as the most fitting analysis framework, because it has advantages over other Human-Computer Interaction (HCI) theories, for example, Actor-Network Theory or Distributed Cognition [53]. Despite the advantages of AT, we found a couple of shortcomings that complicate the application of this theory to the healthcare context.

In the present work, we conduct a systematic literature review to answer the research question: "What are the main problems activity theorists are faced when conducting their socio-technical systems research?". Therefore, we want to detect the specific limitations and challenges of AT in order to improve its application for the analysis of socio-technical systems in healthcare. In general, the results should help to hoist AT from a theory-heavy method to a more universal, but still rigorous, toolbox for both research and practice.

\section{Activity Theory}

AT, also called Cultural-Historical Activity Theory, is a theoretical framework with which researchers can describe activities and the context they are embedded in. The history of AT can be divided into three generations.

\subsection{Development of Activity Theory}

1. Generation: AT is a psychological theory, grounded in Russian-German philosophy and psychology. It was introduced by Lev Vygotsky [51] and his concept of the mediated act. This concept describes the relationship between human agents and objects, also putting forward the idea that humans 
always have to interact with objects by means of mediators [51], e.g., a physician (subject) examines the patient (object) using a stethoscope (mediating object).

2. Generation: Leont'ev [37] expanded on the mediated act by adding hierarchical structure to activities, which describes that an activity constitutes of many individual actions; which are executed by several intrinsic operations. He also considered activities to have a collective notion [37], e.g., the physician (subject) is working in a hospital (community) with his colleagues (division of labor) following medical regulations (rules).

3. Generation: Finally, Engeström [13] took up the concepts of the mediated act and the collective notion of activity to develop a systematic model, namely the Activity System (AS). The AS is illustrated in Figure 1 and described in Table 1.

The contributions of Engeström [13] and Leont'ev [37] laid the groundwork for future activity theorists, and are today highly appreciated in research, especially in the fields of education and human-computer interaction [27].

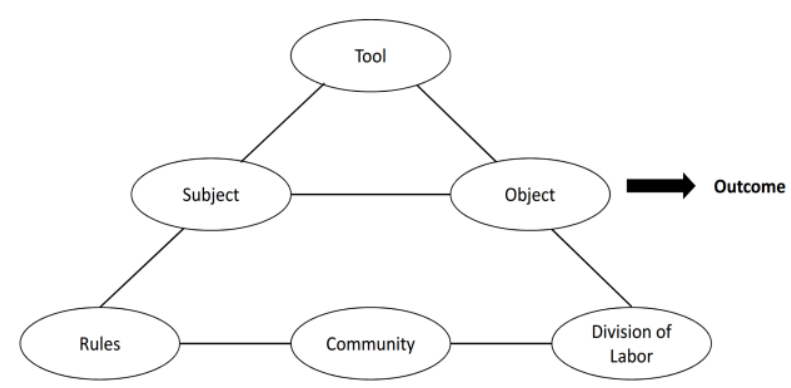

Figure 1. Engeström's Activity System [13]

Table 1. Description of Activity System elements [13]

\begin{tabular}{|l|l|}
\hline $\begin{array}{l}\text { AS } \\
\text { Element }\end{array}$ & Description \\
\hline Subject & The main actor of an activity \\
\hline Tool & $\begin{array}{l}\text { The mediator between subject and } \\
\text { object }\end{array}$ \\
\hline Object & $\begin{array}{l}\text { The entity which has to be transformed } \\
\text { to an outcome. The object is the } \\
\text { common denominator of all motives. }\end{array}$ \\
\hline Rules & $\begin{array}{l}\text { Guidelines, laws, and values which the } \\
\text { subject must follow }\end{array}$ \\
\hline Community & The social context of an activity \\
\hline $\begin{array}{l}\text { Division of } \\
\text { Labor }\end{array}$ & $\begin{array}{l}\text { The hierarchical structure of individuals } \\
\text { in the activity and role definition }\end{array}$ \\
\hline Outcome & $\begin{array}{l}\text { The modified object resulting from the } \\
\text { activity }\end{array}$ \\
\hline
\end{tabular}

\subsection{Principles}

Aside from the AS, AT comprises several principles that can be beneficial for socio-technical system (STS) analysis, because they add explanatory power.

These principles are according to Kaptelinin and Nardi [26]:

- Object-orientedness: Object-orientedness is the principle that focuses on the motives and outcome of an activity [34]. Every activity is motivated by an outcome that is aspired to or expected by the subject. E.g., a doctor is putting a patient on a therapy to improve their health status.

- Internalization/Externalization: Internalization describes the process of learning. Practice helps a subject to internalize knowledge [14]. This process is often connected with the tool of the activity. First, the subject does not know how the tool works and behaves clumsily. With more realized practice, the practitioner adapts towards the tool and operationalizes the handling with it. Externalization illustrates the reproduction of internalized knowledge to the community (teaching), e.g., a physician explains the patient's treatment to the nurse.

- Mediation: This was basically the first developed principle in AT, and is maybe the most important one with its origin from the mediated act. Mediation defines that in every activity the subject interacts with the object by means of tools, rules, or the division of labor [34]. Mediators and tools can be of different nature: technical, social, tacit, non-tacit, etc.

- The hierarchical structure of activity: As explained in subsection 2.1 , an activity with its object and outcome can be split into diverse actions and goals [37]. These actions consist of operations that are internalized and happen subconsciously according to given conditions (see Figure 2).

- Continuous development: An activity is always in transition. In an activity, several contradictions appear [13]. These are the drivers of change. They improve the activity but also lead to new tensions within the AS. 


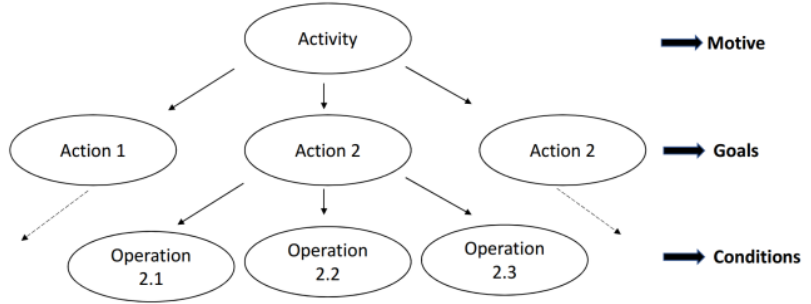

Figure 2. Hierarchical constitution of an activity [27]

\subsection{Contradictions}

According to Engeström [13], contradictions can appear in four aspects:

- Primary contradiction: Describes a contradiction in an AS component. E.g., a PoCS (tool) has a bug.

- Secondary contradiction: Describes a contradiction between two AS components. E.g., a physician (subject) does not understand the functionalities of a PoCS (tool).

- Tertiary contradiction: When one activity is developed further (continuous development), it can cause unwanted tensions. E.g., physicians (subjects) do not want to adapt to a PoCS update (continuous development).

- Quaternary contradiction: Activities share resources in a number of ways. When a resource is occupied by an activity but needed simultaneously by another one, it causes a contradiction: e.g., a patient has to be rounded (activity 1) but the room gets cleaned (activity 2) and cannot be accessed by the nurse meanwhile.

\section{Methodology}

By means of a systematic literature review, we aim at making a stocktaking of problems mentioned by other activity theorists. While other literature reviews focused on AT's application practices [8], or were unstructured [28]; we intend to grasp a holistic and detailed overview on limitations in AT. Therefore, the research question of the present paper is: "What are the main problems activity theorists are faced when conducting their socio-technical systems research?". The results should provide implications for the further enhancement of AT, and motivation for a design science approach to overcome the shortcomings.

\subsection{Data Collection}

The data collection process was aligned to the papers and outlets selected from Clemmensen et al. [8], because they had conducted the most recent systematic review and meta-synthesis/-analysis on AT. Moreover, two of the authors, namely Kaptelinin and Nardi, are well-recognized researchers in the field of AT. Thus, their selection of literature can be considered rigorous and precise. This fact led to the conclusion that all 109 peer-reviewed articles from [8] should be added to our literature basket.

Clemmensen et al. [8] included papers which were published until the end of 2014. As the present literature review was conducted four years later, we also included more recent articles which were published in their selected outlets [8] in the period from 2015 till March 2018. Similar to [8], the outlets were searched for the term "Activity Theory" $(\mathrm{N}=43)$, and articles considered relevant had to contain this term in title, abstract or keywords $(\mathrm{N}=14)$.

The meta-analysis and synthesis of Clemmensen et al. [8] highly focused on HCI journals. As the present work also considered the implications of AT for the analysis and design of information systems in general, we included literature from the "Basket of Eight" which had been defined by senior scholars of the Association of Information Systems [46]. The applied search term and exclusion/inclusion criteria were the same as described above; only the time period was not defined. As a result, 21 relevant journal articles were found.

In a keynote paper, Engeström [12] - the founder of third generation AT - proposes some ideas how the third generation of AT can be developed further toward a fourth generation of AT (4GAT). Based on this paper, some authors took up his ideas and published articles about the design of a new AT framework. These papers were highly relevant to the present research due to their focus on activity theoretical limitations and recommendations. Nonetheless, articles about 4GAT are rare and our previous literature selection process needed to be expanded by adding grey literature. Thus, six popular databases and search engines were considered and searched for suitable terms while the time period was undefined (see Table 2).

\section{Table 2. Search approach for 4GAT articles}

\begin{tabular}{|l|l|}
\hline $\begin{array}{l}\text { Search } \\
\text { Engines }\end{array}$ & $\begin{array}{l}\text { Google Scholar, Science Direct, ACM DL, } \\
\text { Scopus, IEEE Xplore, Springer Link }\end{array}$ \\
\hline Search & "Fourth Generation Activity Theory", \\
"Ferms & "Fourth-Generation Activity Theory", \\
& $\begin{array}{l}\text { "Fourth Generation of Activity Theory", } \\
\text { "4th Generation Activity Theory", } \\
\text { "4th-Generation Activity Theory", } \\
\text { "4th Generation of Activity Theory", } \\
\text { "4th-Generation of Activity Theory" }\end{array}$ \\
\hline
\end{tabular}


In total, 152 of 264 found articles were considered as relevant and further analyzed (see Table 3).

Table 3. Article selection

\begin{tabular}{|l|l|l|}
\hline Source & $\begin{array}{l}\text { Found } \\
\text { articles }\end{array}$ & $\begin{array}{l}\text { Relevant } \\
\text { articles }\end{array}$ \\
\hline Clemmensen et al. [8] & 109 & 109 \\
\hline $\begin{array}{l}\text { Articles (2014-Mar.2018) } \\
\text { out of Clemmensen et al. } \\
\text { [8] outlets }\end{array}$ & 43 & 14 \\
\hline Basket of Eight & 84 & 21 \\
\hline 4GAT Literature & 28 & 8 \\
\hline Total & $\mathbf{2 6 4}$ & $\mathbf{1 5 2}$ \\
\hline
\end{tabular}

It is important to say that, although our studies address AT in the context of healthcare, we wanted to guarantee a high significance of our results. Thus, we chose to not narrow down our focus in this systematic review on healthcare literature but to obtain a broader perspective on high-quality articles in general. Nevertheless, we tried to explain the theoretical concepts and limitations by specific examples in healthcare to highlight the applicability of AT in this research area.

\subsection{Data Analysis}

In contrast to the study of Clemmensen et al. [8], this paper puts its main focus on the limitations and problems which activity theorists had stated in the past.

The coding of articles was conducted by one author and verified by another. At the beginning of the review process, ten randomly selected articles were reviewed by two authors for analyst triangulation [43]. The result was an inter-rater agreement of $75 \%$, which is adequate, inasmuch as most of the coding fields were filled by free text and infrequently by Boolean values. The differences in both coding samples were discussed extensively, and a common viewpoint for the future coding of the remaining literature was adopted.

After conducting the review process (reading all articles and coding them), all direct quotations $(\mathrm{N}=179)$ regarding AT problems were printed and cut out. In multiple clustering sessions, these quotes were mapped to fitting buzzwords on a whiteboard, and a conceptual scheme was formed. This scheme as a map and categorization of AT limitations is described in the results section.

\section{A Conceptual Model for Limitations and Problems in Activity Theory}

\subsection{Theoretical Nature}

The categorization of AT within today's research paradigms, such as subjectivism or positivism, is a complex task [28]. The reason for this is that AT cannot be compared to 'classic' scientific theories which provide implications about cause and effect relationships or provide statements that can be tested in a positivistic manner. AT is rather a conceptual framework for the description and explanation of phenomena than for the prediction of events. However, "[i]t would be useful to go beyond description of phenomena to prediction" [18 pp. 31]. A necessary step for adding predictiveness to AT, as we propose, is its extension by structured and standardized design recommendations.

\section{Design recommendations}

Many activity theorists criticized the lack of design recommendations provided by AT. On the one side, this is the result of the general nature of explanatory theories (such as AT, Actor-Network-Theory, Distributed Cognition, etc.) . None of them provides ample support for design guidelines [21].

On the other hand, activities analyzed by means of AT vary widely. AT has been applied in contexts like healthcare, education, fire emergency, etc. Because the interrelation between activity context and design are high, abstracting guidelines which can be applied in all fields remains challenging [2].

The AS analysis in AT, therefore, needs to overcome the challenge of abstracting a broad range of activities to generate well-suited design implications for STS and CSCW. Especially, articles in the last few years raised their voice regarding this issue $[5,8,21$, $24,49]$. By adding a notion of prescriptiveness through design recommendations, AT might gain usefulness, and, consequently, reach more potential practitioners [21].

\section{Contradictions}

We argue that the identification of contradictions is a crucial point of departure for deriving impactful design proposals. Contradictions are an essential concept in AT because they constitute the drivers of change and continuous transformation in an AS [13].

Nevertheless, many researchers found that the distinction between their cause and symptom is 
difficult to identify, and that contradictions have a fuzzy notion [49]. It often remains unclear as to which of the four levels of contradictions one tension has to be categorized. For example, Hannan [19] quoting [17] debates that third-level contradictions should not be seen as "development anomalies", but rather as contradictions between the motives of individuals/groups. This statement is confusing, because it leads to the impression that third-level contradictions should be classified as second-level ones between the subject('s motive) and the community('s motive). Despite this determination, researchers are in disagreement about the importance of the four contradiction levels. Bringing back the example before, where third-level contradictions should be seen as second-level ones, Hasan et al. [20] concludes that third-level contradictions should be emphasized on much more than, e.g. on the predominate fourth level-contradictions. To conclude, activity theorists have to encounter a common ground and develop a robust methodology for a deliberate contradiction analysis [30, 34, 35, 49].

\subsection{Abstract Nature}

Generally, AT is censured for its abstractness (among others [8, 32]), and its operational shortcomings compared to other explanatory theories [1]. Although abstractness leads to flexibility and adaptability for one's specific research purpose $[1,6]$, AT practitioners partly feel overwhelmed by the spongy theoretical concepts, and have difficulties to evaluate and exactly categorize the qualitative data gathered within the AS model [12].

\section{Comprehensiveness}

Abounding activity theorists argue that AT is not comprehensive enough for many reasons. First, it is stressed that Vygotsky's broad cultural-historical viewpoint of AT has been narrowed and forgotten over time [19]. As a result, Engeström's Activity System "overlooks several significant concepts of activity theory" [1 p. 553], and, consequently, the application of AT in some cases "appears to be oversimplistic" [47 pp. 6]. Furthermore, researchers lamented the lacking integration of physical doing, communication, critical task information, and challenges or obstacles related to an activity [4, 7, 20,33].

It is just not always possible to depict an activity with its dialectical nature in one single Activity System [12, 35]. Activities are always, from a contextual viewpoint, moving and changing. Therefore, identifying specific elements of an activity and mapping them to the unidirectional AS specification remains difficult.

Moreover, the definitions and concepts of AT cannot capture all relevant aspects of an activity. We agree that AT captures the most important activities, and it is a great help for analysis. With that being said, as found by Halverson [18 pp. 32], "AT brings "anointed" objects of analysis into high relief while back grounding and obscuring those not called out by the theory". This, in our opinion, can be of high difficulty for new practitioners who think that AT could be the 'panacea' of analysis, or also for experienced activity theorists who conduct their studies with sort of a tunnel vision.

\section{Standardization}

Because AT is rather abstract and has this lack of comprehensiveness, its application is highly flexible [31]. This flexibility does not only depend on the context of a study, but also on the person who applies AT [3]. Mwanza [41 pp. 3] concludes that "this flexibility has introduced difficulties in replicating, comparing and criticizing the approaches taken to applying Activity Theory".

In line with Mwanza [41], many researchers call for further development in AT and for standardized methods for data gathering, documentation and interpretation [33, 41, 44]. Making the application of AT standardized would furtermore lead to more transparant results.

\subsection{Applicability}

Another limitation of AT is its accessibility for new practitioners and its (generally spoken) complex and fuzzy philosophical concepts $[10,14,38]$. Lee [35 pp. 1] argues, for example, that "Activity theory is not a monolithic template or a well-bounded set of research techniques that one can quickly extract from a textbook and reassemble for use".

Overall, many researchers stated that the notion of "object" in AT is often misunderstood [3, 9, 33]. This lies in the character of this explanatory theory. Because of its Russian-German origins, terms were translated vaguely. Thusly, several books and articles had to be written to discuss the real meaning of an object in AT [33]. Others criticized that "semantic problems with key concepts" complicate the application of AT [8 pp. 12] and that the "relationship arrows between the elements" [9 pp. 19] in the AS model are confusing.

These are all factors which complicate the handling with AT. Especially, in case studies it would be beneficial if non-activity-theorists understood the 
results depicted in an AS [18]. Often they "struggle[...] to understand the basic abstractions of Engeström's models."[9 pp. 19]. One study worked both with Business Process Model and Notation (BPMN) and AT and concluded, that it was much easier to explain BPMN principles to their study participants than it was with the AT principles [40].

Other limitations of AT lie in the application of the Activity System analysis. Many researchers "did not investigate in detail the rules and norms or the precise division of labor that framed the activity" [29 pp. 302]. This statement highlights that often AT provides too in-depth conceptual models, which are hard to contemplate all during one study [34, 38, 39]. Activity analysis through the lens of AT is felt to be cumbersome. This fact has a few negative impacts on AT studies: (1) researchers have to devote a lot of time to their analysis [22], and (2) phenomena which take place for only a short period are difficult to analyze extensively (e.g., a software-rollout in a hospital) [29, 36]. This might be especially the case in CSCW, where work environments are socially complex, "highly collaborative" and fast-changing [48].

\subsection{Missing Context}

Although we stressed in the last section, that AT is too in-depth in some aspects, activity theorists in literature are missing other relevant facets for their analysis:

\section{Organizational Context}

AT literature does not specify the scope of the subject. Originally (see [13],[37]), the subject was described as the social individuum in an activity. This approach is to some extent outdated. E.g. in CSCW and STS we want to generate insights on the individuum as well as the group or working team in an organization. In particular, this is a problem with generalizable terms such as "user" or "employee", where the word does not specify any characteristics of the subject [19]: How can we differentiate between user A and user B? What are their backgrounds? How are they working? Reconciling diverse individuals into one term does not support this important differentiation between individuals, which makes a socio-technical analysis impactful [19]. This generalization problem is also apparent when it comes to conducting case studies and interviews. The results of an interview and the Activity Systems drawn from the interview's content reflect a highly subjectivist viewpoint which cannot be generalized for a whole working force until several employees of the same team are interviewed, and diverse viewpoints are documented [34]; this will continue to lead to time-consuming analysis tasks.

\section{Hierarchical Power Relations}

Albeit AT provides the division of labor element in Activity Systems, it can be hard to describe and illustrate the organizational hierarchy within an activity. One must have a deep look at each individual in the hierarchical structure. E.g., who commands whom and in which tone. Engeström's [12] proposition for 4GAT tried to overcome this issue by describing the division in terms of multiple AS. The problem of this depiction, however, is its generalization. How does this illustration show the interaction between a manager and his employees? Is his leadership role immature and affects sub-activities? The direct impact of hierarchy to a certain activity is missing.

\section{New Technologies}

The "global process of digitalising and digitalised mediation of every aspect of human practice and activity is the hardest challenge activity theory has ever met" [45 pp. 9] (as cited in [15pp. 3]) . Many authors agree with him and criticize the difficulty of capturing recent technological advance using AT [12, 28, 47]. Karanasios [28] introduces the example of social media. Social media is difficult to interpret within the AT framework, because it is as technical as a tool but also as social as a community. The question which arises is: To which AT element do these new technologies belong to [28]? With advanced technical devices such as smart or virtual reality goggles, this issue becomes even more intricated [14]. E.g., by putting on VR glasses, a novice surgeon is situated within two Activity Systems at the same time: (1) The "true" reality where the surgeon stands in a room with VR glasses on and microcontrollers in his hands (tools) to obtain knowledge and skills (object); and (2) the virtual reality where they (subject) are practicing a difficult surgery by means of a scalpel (tool) on a patient (object).

\subsection{Activity Networks}

"AT may struggle to causally explain the 'mycorrhizae activities' involved" [15 pp. 6]. Drawing on the work of Engeström [11, 12], Gleasure and Morgan [15] are referring by this quote to the issue that networks of activities are hard to depict within the frame of AT. To date, there exists no standardized approach for their illustration. 
Especially, when systems are distributed, like in CSCW, where people from different locations work together, the drawing and defining of the interconnectedness between many system instances would be fruitful [10]. In inter-organizational collaboration activities, many task forces work towards the same object and share agency [48]. In the past, this point became even more relevant due to enhanced interactive technologies "that use shared pools of resources" between a variety of activities [25]-[50].

It would be a great enhancement for the AS to be able to document and analyze the dependencies between activities; as it would, for example, enlighten the effects of a novel information system implementation in one activity to its neighboring activities [28]; such as when a PoCS monitor is installed at the patient's bed; what kind of consequences does it have for other tasks, like nurse rounding, meal ordering and room cleaning?

\subsection{Scope of Activity}

Lee [35] argues that the meaning of "activity" in AT is equivocal due to its Russian/German origin. Activity, therefore, can either stand for the state of being active or for conducting a task. This equivocality has consequences for the selection of analysis scope: What exactly is an activity? Is it an entire healthcare organization doing its business, is it the software development team designing and specifying a new PoCS, or is it a specific QA employee conducting a black-box test on the system? Lee [35 pp. 5] continues: "If we assume that activities are properly those that sustain human society, then the unit of analysis that Vygotsky championed tends towards larger, more encompassing categories such as schooling, agriculture, and so no". An analysis on such a general level though is challenging since it does not permit thorough studies of activities on a smaller scale and identification of contradictions to a larger extent [23].

\section{Hierarchical Activity Structure}

Along with the challenging definition of an activity scope, comes the difficulty of breaking activities down into its actions and operations [6]. In AT, activities are composed of actions, and actions out of automated or unconscious operations. This three-element structure (activity-action-operation) is flexible and can change through time. E.g., an older adult uses a novel PoCS. While they are ordering a meal on the device (activity) for the first time, they have to pay attention to the movement of their fingers (action). After some time, they can order food without paying any longer attention to their exact finger movements. This is because the typing procedure became operationalized. As Döweling et al. [10] and Ang et al. [1 pp. 541] argue, there exists no "integrated model" which properly embeds the activity's hierarchy. However, it would be necessary to highlight not only the components included in the Activity System but also to illustrate the activity's "individual and collective actions and operations".

\subsection{Time Dimensions}

As described in previous sections, activities are malleable and change over time. Thus, documentation of activity states for the detailed analysis of activity evolution would improve the answers regarding the following questions: Why was an activity developed? What was the original object and motivation of the AS? What has changed during the time and why? Which contradictions appeared? How were these contradictions solved? Did the solutions accompany new contradictions? To which degree was the implementation of the new activity useful?

All these factors are important in the evaluation of activities, as they shed light on the real reason and meaning behind them. However, to date, it is not possible to illustrate time transitions and changes. Several activity scientists remarked upon this: Ang et al. [1 pp. 541] disapproves that activities are only being documented in terms of a "snapshot of a particular time", which impedes the analysis of historical data and the evolution of an AS. Hannan [19], drawing on [41], points out that the structure of AT is not userfriendly enough to provide insights on the "relation in time". Karanasios [28] highlights, in particular, the transitional characteristics of the activities object. As outlined in previous sections, in AT it is challenging to identify the object and its motives, or even to differentiate between them. An activity timeline could assist activity theorists in their analysis to document the evolution from motives to objectives, and from there, to newer objectives. Therefore, "[...] activity theory should be developed more fully to account for analyzing dynamics over time [...]" [8 pp. 13]. A proposition for a concrete feature implementation was given by Chen et al. [7], who developed a "timeline concept", in which they split up and arranged emergency response activities. This gave them the possibility to examine the activities, and their interrelation from a closer perspective. 


\section{Discussion \& Conclusion}

Previous literature has shown the usefulness of AT in fields such as HCI, STS, and CSCW. The theory can be applied in many fields to conduct insightful case studies through its rich explanatory instruments and concepts. The AS and its principles help researchers to describe the relevant context in activities and highlights unintentional contradictions holistically. As we proposed in previous research, it is especially in healthcare a well-fitting conceptual framework to analyze interaction of patients using information systems [52].

However, it also became apparent to us, that AT has certain limitations. Although sound literature reviews of AT exist $[8,28]$, they have not yet covered a structured analysis of problem areas within the theory.

Because of this, we conducted a structured review of 152 relevant articles to answer the research question: "What are the main problems activity theorists are faced when conducting their sociotechnical systems research?" Our coding results were tested by means of analyst triangulation and 179 quotes regarding AT limitations were found.

These 179 quotes were mapped to seven problem areas in terms of a conceptual scheme (see Table 4).

Table 4. Problem areas of Activity Theory

\begin{tabular}{|l|l|}
\hline Problem Area & Description \\
Nature & $\begin{array}{l}\text { AT is an explanatory theory, which } \\
\text { does not provide sufficient design } \\
\text { recommendations }\end{array}$ \\
\hline Abstract Nature & $\begin{array}{l}\text { The AS is too abstract for a } \\
\text { standardized application in all } \\
\text { research fields }\end{array}$ \\
\hline Applicability & $\begin{array}{l}\text { Activity analysis is too complex } \\
\text { and time-consuming. }\end{array}$ \\
\hline $\begin{array}{l}\text { Missing } \\
\text { Context }\end{array}$ & $\begin{array}{l}\text { AT misses relevant context such as } \\
\text { information about the organization } \\
\text { or new technologies }\end{array}$ \\
\hline $\begin{array}{l}\text { Activity } \\
\text { Networks }\end{array}$ & $\begin{array}{l}\text { An activity shall be seen within a } \\
\text { network of neighboring activities. }\end{array}$ \\
\hline $\begin{array}{l}\text { Scope of } \\
\text { Activity }\end{array}$ & $\begin{array}{l}\text { Often it is unclear what an activity } \\
\text { is and how activities, actions, and } \\
\text { operations have to be categorized }\end{array}$ \\
\hline $\begin{array}{l}\text { Time } \\
\text { Dimensions }\end{array}$ & $\begin{array}{l}\text { Changes in an activity through } \\
\text { time cannot be documented }\end{array}$ \\
\hline
\end{tabular}

Our results show that the application of AT is by no means trivial. AT is fuzzy, too theoretical and has concepts that are too flexible and hard to grasp for novel activity theorists. Besides, results are not replicable because of missing standardization. In general, we found that research was both criticising the richness of AT, but as well the ignorance of important contextual information such as organizational constructs or new technological advances. Other issues were that interrelated activities cannot be analyzed holistically, the uncertainty about the scope of activities and their hierarchical structure, as well as the difficult documentation of activities throughout time. These results imply that some aspects in Engeström's [13] AS and its principles are to some extent outdated (mediation, continuous development etc.) and need to be retooled.

The outcome of our study has implications for both theory and practice, and can serve as a valuable starting point for a design science approach [8]. By developing a software or method artifact, AT can be enriched to overcome the seven problem areas defined in this paper. This would lift the functionality and usability of AT to a powerful framework, which in turn can be applied in the context of healthcare to achieve better system analysis results.

\section{Acknowledgments}

This research and development project is funded by the German Federal Ministry of Education and Research (BMBF) within the program "Project RADAR - Data Driven Environmental Scanning for the Decisions of Tomorrow" (funding number: 02K16C190) and managed by the Project Management Agency Karlsruhe (PTKA). The authors are responsible for the contents of this publication.

\section{References}

[1] Ang, C.S., P. Zaphiris, and S. Wilson, "A case study analysis of a constructionist knowledge building community with activity theory", Behaviour \& Information Technology, 30(5), 2011, pp. 537-554.

[2] Bardram, J.E. and A. Doryab, "Activity Analysis Applying Activity Theory to Analyze Complex Work in Hospitals", in Proceedings of the ACM 2011 conference on Computer supported cooperative work. 2011.

[3] Baumer, E.P.S. and B. Tomlinson, "Comparing Activity Theory with Distributed Cognition for Video Analysis: Beyond "Kicking the Tires"", in Proceedings of the SIGCHI Conference on Human Factors in Computing Systems, CHI'11. 2011.

[4] Bødker, S. and P.B. Andersen, "Complex Mediation", Human-Computer Interaction, 20(4), 2005, pp. 353-402.

[5] Bøker, S. and C.N. Klokmose, "The Human-Artifact Model: An Activity Theoretical Approach to Artifact Ecologies", Human-Computer Interaction, 26(4), 2011, pp. 315-371. 
[6] Chaiklin, S., "Modular or Integrated?: - An Activity Perspective for Designing and Evaluating Computer-Based Systems", International Journal of Human-Computer Interaction, 22(1-2), 2007, pp. 173-190.

[7] Chen, R., R. Sharman, H.R. Rao, and S.J. Upadhyaya, "Data Model Development for Fire Related Extreme Events: An Activity Theory Approach", MIS Quarterly, 37(1), 2013, pp. 125-147.

[8] Clemmensen, T., V. Kaptelinin, and B. Nardi, "Making HCI theory work: An analysis of the use of activity theory in HCI research", Behaviour \& Information Technology, 35(8), 2016, pp. 608-627.

[9] Collins. Patricia: Shukla, S. and D. Redmiles, "Activity Theory and System Design:: A View from the Trenches", Computer Supported Cooperative Work: CSCW: An International Journal, 11(1-2), 2002, pp. 55-80.

[10] Döweling, S., B. Schmidt, and A. Göb, "A Model for the Design of Interactive Systems based on Activity Theory", in Proceedings of the ACM 2012 conference on Computer Supported Cooperative Work. 2012.

[11] Engeström, Y., "Expansive Visibilization of Work: An Activity-Theoretical Perspective", Computer Supported Cooperative Work (CSCW), 8(1-2), 1999, 63-93.

[12] Engeström, Y., "The Future of Activity: A Rough Draft", in ISCAR Conference 2008. 2008.

[13] Engeström, Y., "Learning by Expanding: An ActivityTheoretical Approach to Developmental Research", Cambridge University Press, 2014.

[14] Fjeld, M., K. Lauche, M. Bichsel, F. Voorhorst, H. Krüger, and M. Rauterberg, "Physical and Virtual Tools: Activity Theory Applied to the Design of Groupware", Computer Supported Cooperative Work (CSCW), 11, 2002, pp. 153-180.

[15] Gleasure, R. and L. Morgan, "The pastoral crowd: Exploring self-hosted crowdfunding using activity theory and social capital", Information Systems Journal, 42(2), 2017, pp. 1-27.

[16] Gregor, S., "The Nature of Theory in Information Systems", Management Information Systems Quarterly, 30(3), 2006.

[17] Halloran, J., The Activity Space: Analyzing Intentionality in Open Cooperative Work, 2000.

[18] Halverson, C.A., "Activity theory and distributed cognition: or What does CSCW need to do with theories?", Computer Supported Cooperative Work: CSCW: An International Journal, 11(1-2), 2002, pp. 243-267.

[19] Hannan, M., "Analysis of the collaborative activities in software development processes from the perspective of chronotopes", Computers in Human Behavior, 27(1), 2011, pp. 248-267.

[20] Hasan, H., S. Smith, and P. Finnegan, "An activity theoretic analysis of the mediating role of information systems in tackling climate change adaptation", Information Systems Journal, 27(3), 2017, pp. 271-308.

[21] Herrmann, T., M. Hoffmann, G. Kunau, and K.-U. Loser, "A modelling method for the development of groupware applications as socio-technical systems", Behaviour \& Information Technology, 23(2), 2004, pp. 119135 .

[22] Honold, P., "Culture and Context:: An Empirical Study for the Development ofa Framework for the Elicitation of Cultural Influence in Product Usage", International Journal of Human-Computer Interaction, 12(3-4), 2000, pp. 327-345.

[23] Igira, F.T., "The situatedness of work practices and organizational culture: Implications for information systems innovation uptake", Journal of Information Technology, 23(2), 2008, pp. 79-88.

[24] Jensen, T., R. Vatrapu, and N. Bjørn-Andersen, "Avocados crossing borders: The problem of runaway objects and the solution of a shipping information pipeline for improving international trade", Information Systems Journal, 28(2), 2018, pp. 408-438.

[25] Kaptelinin, V. and L.J. Bannon, "Interaction Design Beyond the Product: Creating Technology-Enhanced Activity Spaces", Human-Computer Interaction, 27(3), 2012, pp. 277-309.

[26] Kaptelinin, V. and B.A. Nardi, Acting with technology: Activity theory and interaction design, 1 st edn., MIT Press, Cambridge, Mass., London, 2009.

[27] Kaptelinin, V. and B.A. Nardi, "Activity Theory in HCI: Fundamentals and Reflections", in Activity Theory in HCI. 2012.

[28] Karanasios, S., "Toward a unified view of technology and activity", Information Technology \& People, 31(1), 2018, pp. 134-155.

[29] Karanasios, S. and D. Allen, "ICT for development in the context of the closure of Chernobyl nuclear power plant: An activity theory perspective", Information Systems Journal, 23(4), 2013, pp. 287-306.

[30] Karanasios, S. and D. Allen, "Mobile technology in mobile work: Contradictions and congruencies in activity systems", European Journal of Information Systems, 23(5), 2017, pp. 529-542.

[31] Karlsson, F. and K. Wistrand, "Combining method engineering with activity theory: Theoretical grounding of the method component concept", European Journal of Information Systems, 15(1), 2017, pp. 82-90.

[32] Kharrufa, A., S. Rix, T. Osadchiy, A. Preston, and P. Olivier, "Group Spinner: Recognizing \& Visualizing Learning in the Classroom for Reflection, Communication \& Planning", in Proceedings of the 2017 CHI Conference on Human Factors in Computing Systems - CHI '17, G. Mark, S. Fussell, C. Lampe, m.c. schraefel, J.P. Hourcade, C. Appert, and D. Wigdor, Editors, the $2017 \mathrm{CHI}$ Conference, Denver, Colorado, USA, 06/05/2017 - 12/05/2017. 2017. ACM Press: New York, New York, USA. 
[33] Khayyat, M., "A Proposed Model for the Fourth Generation of Activity Theory to be Applied on the Smart City Research", in Thirty Seventh International Conference on Information Systems,. 2016: Dublin.

[34] Korpelainen, E. and M. Kira, "Systems approach for analysing problems in IT system adoption at work", Behaviour \& Information Technology, 32(3), 2013, pp. 247262.

[35] Lee, Y.-J., "Activity Theory and Science Learning", in Encyclopedia of Science Education, R. Gunstone, Editor. 2015. Springer Netherlands: Dordrecht.

[36] Lee, Y.-J., "More than just story-telling: Culturalhistorical activity theory as an under-utilized methodology for educational change research", Journal of Curriculum Studies, 43(3), 2011, pp. 403-424.

[37] Leont'ev, A.N. and M.J. Hall, Activity, Consciousness, and Personality, Prentice-Hall, 1978.

[38] MACAULAY, C., D. Benyon, and A. CRERAR, "Ethnography, theory and systems design: From intuition to insight", International Journal of Human-Computer Studies, 53(1), 2000, pp. 35-60.

[39] Mahatody, T., M. Sagar, and C. Kolski, "State of the Art on the Cognitive Walkthrough Method, Its Variants and Evolutions", International Journal of Human-Computer Interaction, 26(8), 2010, pp. 741-785.

[40] Malaurent, J. and D. Avison, "Reconciling global and local needs:: A canonical action research project to deal with workarounds", Information Systems Journal, 26(3), 2016, pp. 227-257.

[41] Mwanza, D., "Where Theory meets Practice:: A Case for an Activity Theory based Methodology to guide Computer System Design", in Proceedings of INTERACT' 2001: Eighth IFIP TC 13 Conference on Human-Computer Interaction, Tokyo, Japan, 9-13 July. 2001.

[42] Omachonu, V.K. and N.G. Einspruch, "Innovation in healthcare delivery systems: A conceptual framework", Innovation Journal, 15(1), 2010, pp. 1-20.

[43] Patton, M.Q., Qualitative evaluation and research methods, 2nd ed, Sage Publications, Inc, Thousand Oaks, CA, US, 1990.
[44] Peña-Ayala, A., H. Sossa, and I. Méndez, "Activity theory as a framework for building adaptive e-learning systems: A case to provide empirical evidence", Computers in Human Behavior, 30, 2014, pp. 131-145.

[45] Rückriem, G., "Digital technology and mediation: A challenge to activity theory", 2009.

[46] https://aisnet.org/?SeniorScholarBasket, accessed 3-152018.

[47] Simeonova, B., "Transactive memory systems and Web 2.0 in knowledge sharing:: A conceptual model based on activity theory and critical realism", Information Systems Journal, 53, 2017, pp. 1-20.

[48] Spinuzzi, C., "Working Alone Together", Journal of Business and Technical Communication, 26(4), 2012, pp. 399-441.

[49] Turner, P. and S. Turner, "A web of contradictions", Interacting with Computers, 14(1), 2001, pp. 1-14.

[50] Voida, S. and E.D. Mynatt, "“It Feels Better Than Filing":: Everyday Work Experiences in an Activity-Based Computing System", in Proceedings of the 27th international conference on Human factors in computing systems - CHI 09, D.R. Olsen, R.B. Arthur, K. Hinckley, M.R. Morris, S. Hudson, and S. Greenberg, Editors, the SIGCHI Conference, Boston, MA, USA, 04/04/2009 - 09/04/2009. 2009. ACM Press: New York, New York, USA.

[51] Vygotsky, L.S. and M. Cole, Mind in Society: Development of Higher Psychological Processes, 1978.

[52] Wiser, F., C. Durst, and N. Wickramasinghe, "Analyzing Collaborative Patient Care Solutions Using Activity Theory", Hawaii International Conference on System Sciences 2017 (HICSS-50), 2017.

[53] Wiser, F., C. Durst, and N. Wickramasinghe, "Activity Theory: A Comparison of HCI Theories for the Analysis of Healthcare Technology", in Theories to Inform Superior Health Informatics Research and Practice, N. Wickramasinghe and J.L. Schaffer, Editors. 2018. Springer International Publishing: Cham. 